\title{
Prospective evaluation of a decision support system providing advice on ventilator settings of: inspiratory oxygen, delivered pressure or volume, frequency and peep
}

\author{
DS Karbing ${ }^{1 *}$, S Spadaro ${ }^{2}$, SE Rees ${ }^{1}$, CA Volta $^{2}$ \\ From ESICM LIVES 2015 \\ Berlin, Germany. 3-7 October 2015
}

\section{Introduction}

Management of mechanical ventilation is complex. Guidelines to aid in managing settings may fail to adapt general goals to the individual patient physiology. The Beacon Caresystem (Mermaid Care, Denmark) is a commercial version of a physiological-model based system for advising on mechanical ventilation (1). Mathematical models are tuned to patient measurements allowing advice to be patient specific. Beacon 5 provides advice for control and support modes of ventilation, with advice on: inspiratory oxygen $\left(\mathrm{FiO}_{2}\right)$; inspiratory pressure (PS/PC) or tidal volume (Vt); Positive end-expiratory pressure (PEEP) and, in control modes, respiratory frequency (Rf).

\section{Objectives}

This study investigates short-term changes in ventilator settings and consequent patient status from following advice of the Beacon Caresystem.

\section{Methods}

Thirty patients residing in an ICU in Ferrara, Italy have been included, with a total of 40 patients planned for protocol. Informed consent and ethical approval was obtained in all cases. Advice of the system were followed, if judged appropriate, over a period of 4 hours or until advice was to use current settings. Baseline was routine care. A total of 25 patients were included for analysis with the remainder excluded due to death prior to protocol (1), not meeting inclusion criteria at study start (1) and technical issues with the system (3). Average and spread are reported as

'Aalborg University, Respiratory and Critical Care Group (rcare), Department of Health Science and Technology, Aalborg, Denmark

Full list of author information is available at the end of the article mean \pm SD or median $\left[25^{\text {th }}-75^{\text {th }}\right.$ perc. $]$ with paired t-test or Wilcoxon's test applied as appropriate for comparing baseline to protocol end.

\section{Results}

Seven and 18 patients were in control and support mode, respectively. Eleven patients (44\%) were diagnosed with ARDS. SOFA score and age at day of study were $7.0 \pm 2.8$ and $67 \pm 13$ yrs, respectively. Sixteen (64\%) of patients were male. Advice was provided $5 \pm 2$ times. $\mathrm{FiO}_{2}$ and PS/ PC were reduced from 50 [40-50] to 43 [31-49] \% and $12 \pm 4$ to $9 \pm 6 \mathrm{~cm} \mathrm{H}_{2} \mathrm{O}$, respectively $(\mathrm{P}<0.05)$. Vt was reduced from $497 \pm 121$ to $452 \pm 120 \mathrm{ml}(7.9 \pm 1.9$ to $7.2 \pm 1.8 \mathrm{ml} / \mathrm{kg} \mathrm{IBW})(\mathrm{P}<0.05)$. Rf was increased from 16 [13-21] to 19 [15-24] $\mathrm{min}^{-1}(\mathrm{P}<0.05)$. PEEP was not changed significantly with values of 8 [6-9] and $8[7-10] \mathrm{cm}$ $\mathrm{H}_{2} \mathrm{O}$ at baseline and study end, respectively. Plateau pressure was reduced from $19 \pm 5$ to $17 \pm 7 \mathrm{~cm} \mathrm{H}_{2} \mathrm{O}$ $(\mathrm{P}<0.05)$. Pulse oximetry oxygen saturation and end-tidal $\mathrm{CO}_{2}$ did not change significantly with baseline to end values of $97 \pm 3$ to $96 \pm 3 \%$ and $5.0 \pm 1.1$ to $5.1 \pm 1.1 \%$, respectively.

\section{Conclusions}

These initial results indicate that Beacon Caresystem provides rational advice, lowering ventilator support whilst maintaining adequate ventilation and oxygenation.

\section{Grant Acknowledgment}

DSK and SER are minor shareholders and perform consultancy for Mermaid Care. 


\section{Authors' details}

'Aalborg University, Respiratory and Critical Care Group (rcare), Department of Health Science and Technology, Aalborg, Denmark. ${ }^{2}$ University of Ferrara Department of Morphology, Experimental Medicine and Surgery, Section of Anaesthesia and Intensive Care, Arcispedale Sant' Anna, Ferrara, Italy.

Published: 1 October 2015

\section{Reference}

1. Rees SE: The Intelligent Ventilator (INVENT) project: The role of mathematical models in translating physiological knowledge into clinical practice. Computer Methods and Programs in Biomedicine 2011, Supplement, Vol 4:S1-S29.

doi:10.1186/2197-425X-3-S1-A672

Cite this article as: Karbing et al:: Prospective evaluation of a decision support system providing advice on ventilator settings of: inspiratory oxygen, delivered pressure or volume, frequency and peep. Intensive Care Medicine Experimental 2015 3(Suppl 1):A672.

\section{Submit your manuscript to a SpringerOpen ${ }^{\mathcal{O}}$ journal and benefit from:}

- Convenient online submission

- Rigorous peer review

- Immediate publication on acceptance

- Open access: articles freely available online

- High visibility within the field

- Retaining the copyright to your article

Submit your next manuscript at $\gg$ springeropen.com 